\title{
THE DRIVING FORCES OF EXECUTION \\ COMPETENCE OF CORRUGATED FIBERBOARD \\ BOXES MANUFACTURING INDUSTRY IN SRI LANKA
}

\author{
BM \\ D. G. J. K. J. Kulasinghe \\ GS/MC/1874/2001
}

The thesis submitted for the M.Sc. (Management) program of the Faculty of Graduate Studies, University of Sri Jayawardenapura in partial fulfitllmentt off thenexquirements of the Degree of Master of Science in Management

M.Sc. (Management) Degree Program

Faculty of Graduate Studies

University of Sri Jayawardenapura

Sri Lanka

JANUARY 2007 
I hereby recommended that the thesis was prepared under my supervision

by Don Geethan Jagath Kumar Jayasekara Kulasinghe

The Driving Forces of Execution Competence of Corrugated Fiberboard Boxes Manufacturing Industry in Sri Lanka

Be accepted in partial fulfillment of the requirements of the degree of Master of Science in Management

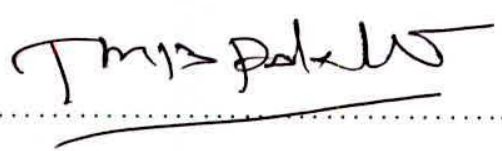

Mr. T. M. B. Palawatta

Thesis advisot Bi PALAWATTA

HEAD.

DEPT. OF INFORMATION TECHNOLOGY \&

DECIS:ON SCIENCES,

oNIVERSITY OF SRI JAYAWARDENAPURA

Approved by the Examining Committee

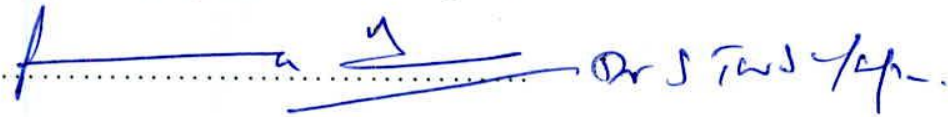

M.Sc. (Management) Degree Program

Faculty of Graduate Studies

University of Sri Jayawardenapura

Sri Lanka

January, 2007 
In Dedication to

My Loving Wife Nishanthi

\&

My Loving Son Binura

- iii - 


\title{
THE DRIVING FORCES OF EXECUTION
}

\section{COMPETENCE OF CORRUGATED FIBERBOARD}

\author{
BOXES MANUFACTURING INDUSTRY
}

IN SRI LANKA 


\section{CHAPTER 01}

\section{INTRODUCTION}

\subsection{BACKGROUND - DRIVING FORCES OF EXECUTION COMPETENCE}

The manufacturing systems have become very complex as a variety of materials, machines, tooling and other inputs are being employed for production purpose. This complexity along with market uncertainties due to short product life cycles and rapid product innovations require the manufacturing system to respond quickly to uncertainties and changes. For that, flexibility is needed. Flexibility is the ability of a system to respond or react to a change with little penalty in time, effort or cost (Upton, 1994). The change may be internal (equipment breakdown, workers' absenteeism etc.) or external (change in product design, demand and product mix). Flexibility is also the ability to do things differently or do something else should the need arise (Bahrami, 1992). Flexibility is the exercise of free will or freedom of choice on the continuum to synthesize the dynamic interplay of thesis and antithesis in an interactive and innovative manner, capturing the ambiguity in systems and expanding the continuum with minimum time and efforts (Sushil, 1997). On one side, flexibility means being agile and versatile, while on the other side, it means being robust and resilient so as to withstand shocks when negatively affected by changes. There are various types of flexibilities. A comprehensive classification of flexibility is provided (Browne et al, 1984) by describing eight types of flexibilities - machine flexibility, process flexibility, product flexibility, routing flexibility, volume flexibility, expansion flexibility, process sequence flexibility, and production flexibility.

Various companies are experimenting with novel organizational structures and management processes to accommodate flexibility. Some of the prevalent developments include delayering, team-based network, alliances and partnerships.

Besides flexibility, proper utilization of resources is essential due to unprecedented competition coupled with acute resource crisis. Enhancement in productivity is the key to success. One of the methods of improving productivity is to measure productivity. Productivity can be measured either as total productivity or partial productivity, i.e. material productivity, labour productivity, energy productivity, and equipment productivity (Gupta and Singh, 2001).

According to the research performed on execution competencies by Narasimhan el al, (2004), manufacturing flexibilities improve firm's ability to react to customer demands without incurring excessive time and cost penalties. While development of manufacturing flexibilities was desirable and indeed critical for some firms, exploiting the flexibility capabilities to achieve tangible firm- 
level performance outcomes through effective execution was becoming increasingly important. In their paper presented a conceptual model that introduces two new constructs: flexibility competence and execution competence as distinct from manufacturing flexibility. Based on the proposed conceptual model and a multistage data envelopment analysis (MDEA) of empirical data, the roles of flexibility and execution competencies in determining performance were examined. The results indicated that some firms were more effective than others in exploiting investments in advanced manufacturing technologies and strategic sourcing initiatives to develop manufacturing flexibilities. Thus, lending credibility to the new construct referred to as flexibility competence they also concluded that some firms were more effective than others in converting manufacturing flexibilities into tangible firm-level performance, suggesting that execution competence was an important construct that needs attention. They suggested future research in this area for comprehensively investigating these two new constructs proposed in that paper and identifying the factors that influence them.

Manufacturing flexibilities improve a firm's ability to react to customer demands without incurring excessive time and cost penalties (Narasimhan et al., 2004).

Flexibility Competence and Execution Competence has been defined by Narasimhan et al., (2004) as follows:

Flexibility competence is the ability of a firm to convert or exploit investments in advanced manufacturing technologies and strategic sourcing initiatives to develop manufacturing flexibilities.

Execution competence is the ability of a firm to convert its flexibility (and other manufacturing) capabilities into tangible, firm-level performance outcomes that can affect its competitive success. 


\subsection{THE PROBLEM PROPER}

In this research, the researcher has chosen, to identity the role (effect) of the driving forces of execution competence on Flexibility and Performance relationship. Thus the research issue goes as follows.

\subsection{RESEARCH ISSUE}

To investigate whether motivation, knowledge, information and trust are the driving forces of execution competence.

\subsection{THE RESEARCH OBJECTIVES}

This study attempted to achieve the following objectives.

a. To investigate whether the flexibility and performance has a linear relationship.

b. To investigate the effect of Motivation on the relationship between flexibility and performance.

c. To investigate the effect of Knowledge on the relationship between flexibility and performance.

d. To investigate the effect of Information on the relationship between flexibility and performance.

e. To investigate the effect of Trust on the relationship between flexibility and performance.

f. To cross examine the behaviors of identified driving forces between six companies.

\subsection{SIGNIFICANCE OF THE STUDY}

The corrugated fibreboard box manufacturing industry in Sri Lanka is facing major challenges that may threaten the survival of the business under the falling trade barriers between countries. Sri Lanka had already signed Free Trade Agreements with India and Pakistan. 
Clearly the situation discussed above is not healthy for the stability and future development of this industry. If the industry collapses -

- It will affect the majority of manufacturers currently in operation with over 8,000 employees. Many small companies who are in the supply chain, the service providers, and the dependants of the families will exceed 100,000 indirect dependents from the industry.

- If some of these consumers decide to convert their mode of packaging to plastic containers, it will increase the environmental hazards Sri Lanka is already facing with extensive usage of polythene and polyethylene.

- Sri Lanka is spending close to US $\$ 30,000,000$ annually in importing paper for this industry as raw material. If boxes are to be imported, this figure will increase considerably by means of extra stock holding, delay in exports due to delay in imported consignments of boxes, etc. in addition to the extra amounts paid to import value added product. This will eventually cause adverse impact on the Balance of Payment deficit of the country, which is already very high.

\subsection{METHODOLOGY}

To prove the hypotheses (please see the details in chapter 3 ), primary data were collected using two questionnaires. The samples consist of 6 companies in corrugated fiberboard box manufacturing industry in Sri Lanka.

The unit of analysis was "Individual company" for questionnaire 02 (Six GMs were interviewed), and "Individual employee" for questionnaire 01(60 cross functional employees were selected).

Data presentation was based on charts, tables etc. Data analysis was based on SPSS version 11.

Descriptive analysis, One Way ANOVA, One Way ANOVA along with multiple comparison Tukey HSD test, Non-parametric correlation, Regression Analysis and Stepwise Regression Analysis were used to analyze the underlined data, accordingly.

Hypothesis testing was used to prove hypotheses. 


\subsection{STRUCTURE}

This theses consists of seven chapters

- CHAPTER 1 - INTRODUCTION

This chapter is the overview of the study. It explains the research issues, its objectives and the significance.

- CHAPTER 2 - LITERATURE REVIEW

This chapter consists of theoretical background of Job Performance using various models and empirical studies done on performance by the information gathered from literature survey.

- CHAPTER 3 - CONCEPTUAL FRAME WORK AND HYPOTHESES

This chapter details the definitions given by scholars to each independent variable. Attempt is made to conceptualized these concepts. The research model is given. Pervious researches in relation to this topic are discussed.

- CHAPTER 4 - METHODOLOGY

This chapter describes the sample and the questionnaire used to measure data explained. The methods that will be used to analyzed data are summarized.

- CHAPTER 5 - DATA ANALYSIS \& PRESENTATION

This chapter analyze data and presents them using various tables and figures in Appendix 2.

- CHAPTER 6 - DISCUSSION

Here it discusses the findings of the study in comparison with previous researches.

- CHAPTER 7 - CONCLUSION AND SUGGESTIONS FOR FURTHER RESEARCH

This chapter concludes the study by giving suggestions and hints for further research. 


\section{CHAPTER 02}

\section{LITERATURE REVIEW}

\subsection{INTRODUCTION}

In this chapter the main focus will be a discussion on the dependent variable Performance and it's related independent variables (Flexibility, Motivation, Knowledge, Information and Trust). These variables were investigated to find the research gap, which will be the main focus of the research, in the conceptual framework defining Execution Competence and it's driving forces, suggested in the chapter 3. See Fig. 3.2.

\subsection{FLEXIBILITY}

Flexibility has become one of the most sought after properties in modern manufacturing systems (Shewchuk, 1999). This is due to the fact that decreasing time-to-market, shorter product life cycles and a move towards mass-customization have increased the need for flexibility. Flexibility is desired in order to handle uncertainties and variations in both internal and external environment (Ramasesh and Jayakumar, 1991). Therefore, it can be seen as the ability to continue functioning effectively regardless of changes or as the ability to change and adjust the production to the new circumstances.

Flexibility is a multi-dimensional concept (Gerwin, 1993; Upton, 1994), and can be interpreted on different levels of a manufacturing system. In effect it holds a different meaning at each point depending on the means by which it is to be achieved (Cheng et al., 1997). Different manufacturing situations are associated with different levels of uncertainty and variations, and therefore, call for different sorts of flexibility. Flexibility is generally seen as situation specific in nature (Gupta and Buzacott, 1996). Gerwin (1993) advocates the need for further research to be aimed at an applied orientation, and the need to link flexibility (in terms of the methods and technology used), as well as to the benefits they carry in different situations. Correa (1994) requests a clear link between desired or required system flexibility levels, and the resources necessary to achieve them.

Correa (1994) also addresses the cost of achieving flexibility, and advocates managers making justified decisions, as well as the need to understand the cost of creation and maintenance of flexibility and unplanned change control.

Managerial choices of flexibility or uncertainty/variation control consist of different ways of handling change by using different flexibilities (Correa, 1994). However, little research has 
been directed towards understanding which flexibility suits specific situations, and how the appropriate flexibility is achieved. This relates to the research requested by Correa (1994) and Gerwin (1993).

In this paper, the results of the most up-to-date surveys are presented in an attempt to define different possible situations of uncertainty/variability. Each of these defined situations is associated with certain flexibility types, which in turn can be achieved by using a number of methods, tools and techniques.

\subsection{VARIABILITY AND UNCERTAINTY: REASONS FOR FLEXIBILITY WITHIN AN ORGANIZATION}

There are a number of reasons for a company to improve its flexibility, and every manufacturing situation is likely to face a situation with unique needs for flexibility. However, the flexibility is mainly needed in order to deal with two variables: intrinsic uncertainties and the variability of outputs. Variations and uncertainties can be seen as attributes of changes, and since variation and uncertainty are often translated into changes, it has been proposed to refer to the concept of change as a reason for flexibility (Correa, 1994).

Another notion to make on the subject is the difference between planned and unplanned changes. Authors on flexibility seldom differentiate between unplanned and planned changes, but mostly only consider unplanned change to the required flexibility. Unplanned change happens independently of an organization's determination but to which the organization has to adapt. On the contrary, planned changes happen as a result of the organization's conscious managerial decisions, which are taken to alter some aspect of the organization or its relation with the environment (Correa, 1994).

\subsection{FACTORS CAUSING UNPLANNED CHANGE}

As the nature of variability and uncertainty is situation specific, it will be impossible to cover in detail what situations that manufacturing companies might face. However, apart from authors simply referring to "turbulent environments", or "changing customer demands", as sources of change, researchers have also made a more specific description of the origins of different changes and uncertainty.

A general picture of what causes a need for flexibility is given by Viswanadham and Raghavan, 1997, who discuss the "anatomy of changes". This categorization focuses on the nature of the change, and for instance, resource changes which include changes originating in 
process and labor, as well as suppliers. A different categorization, focusing on the origin of change, is given by Palaniswami (1994) defining five factors: products, manufacturing processes, planning and control, human resources, and the relations with the suppliers (De Toni and Tonchia, 1998). Correa (1994) similarly defines seven main sources of unplanned change called stimuli, which are comparable to Palaniswami's five factors.

There is an obvious difference between the approaches that are being focused on, the first case, the nature of change, and the second case, the origin of change. Although most authors that attempt to describe the changes an organization experience using their own terms and categories, there are no particular agreements or standardization, which exists.

\subsection{UNCERTAINTY}

Manufacturing organizations have often been indicated to be open systems faced with uncertainty and ambiguity, yet requiring certainty and clarity to operate in a rational manner (Slack, 1997). In the case of uncertainty, flexibility can be seen as coinciding with the ability to deal with the unexpected, both within the manufacturing system and outside (De Toni and Tonchia, 1998). Uncertainty is a complex concept, which has received different approaches in literature. The most controversial point appears to be a discussion on whether the measurement of uncertainty is the adequacy of either perceived or objective approaches (Swamidass and Newell, 1987). The objective measures of uncertainty are indexes for uncertainty based on attributes of the environment. At the same time the value of these attributes are dependent on the previous knowledge and cognitive process of uncertainty for the estimator.

Environmental uncertainty has been argued to be one of the main reasons for a firm to seek flexibility (Gerwin, 1987; Slack, 1989), and some researchers provide certain empirical support for such theories (Swamidass and Newell, 1987). It should, however, be noted that other researchers have failed in showing a significant relationship between environmental uncertainty and actual manufacturing flexibility in the attempt to validate empirically the relationships between them (Pagell and Krause, 1999). Newman et al. (1993) suggest that the relationship between flexibility and environmental uncertainty is complicated by the use of buffers in the form of time or stock, and that the relationship thereby could be difficult to measure.

\subsection{VARIABILITY}

Variability can be seen as the flexibility of offering a variety of products and carrying out different manufacturing processes (De Toni and Tonchia, 1998). Like uncertainty, variability 
has been considered as another main reason for manufacturing companies to seek flexibility (Slack, 1989; Goldhar and Jelinek, 1983; Zelonovic, 1982).

The variability of outputs of a manufacturing system can be seen in at least two different dimensions. The first dimension refers to the actual variety of outputs, i.e. the range of parts produced. The second dimension refers to the variation of the system's outputs over time in terms of volume, part or product variation, mix and timing (Correa, 1994). This can be related to Griffiths et al.'s (2000) two-dimensional view of customer demand: mix and volume demand.

Gustavsson (1984) also describes a twofold relationship between productivity and flexibility, where products are subject to change due to internal factors of technology changes, component "rationalization", and changes in fashion. The external factors determining flexibility needs may be fluctuations of the market, seasonal fluctuations, and competition. Upton (1994) exemplifies the external requirements as sources of variability to which a firm must respond to as a cyclic aggregate demand for products, frequent demands for customization or opportunities to gain market shares by broadening the product line.

\subsection{NATURE OF VARIABILITY}

Viswanadham and Raghavan (1997) make a notion on resource changes, defined to include variations in the human and machine resources due to absenteeism and machine failure, transport breakdowns, rushed orders, supplier disturbances, and other routinely arising issues.

Design and demand changes in the product refer to planned change in terms of proactive introduction of new products, or unplanned changes caused by random customer demand and bad forecasting.

Technological changes are seen as either continuous or discontinuous, where the PC and hard disk drives are examples of discontinuous changes. For the company to cope with this, it should be able to predict and develop competencies for future products and evaluate risks involved in new ventures.

Socio-political changes are considered as deregulations, which have had a big impact on many industries. Liberalization of certain markets may open up new opportunities, as well as some situations, which are rather dependent on legislation. According to Narasimhan and Das (2000), market booms or recessions create a need for volume flexibility, and discounting and promotion create volume fluctuations. 


\subsection{CONSUMER AND COMPANY-LED CHANGE}

Griffiths et al. (2000) define the variation in demand a manufacturing company experiences, and takes into consideration the effects it has on the supply chain. They describe an average and resultant demand with variations about it. Over a given period, an individual consumer's demand is summed with those of other consumers resulting in a summed demand signal

They also divide the causes of variation in demand into two categories:

1. Consumer-led change, or true demand, where seasonality, changes in the economy, and changes in markets make up the long-term changes. Short-term changes are considered as weather, environment, and buying habits of the customers.

2. Company-led change, or induced variation, which consists of sales and marketing strategy (e.g. promotions), delivery methods (unit loads, vehicle sizes), and supply-chain structures (e.g. number of warehouses, number of suppliers).

\subsection{FACTORS CAUSING FLEXIBILITY NEEDS}

Regardless of whether a requirement for change can be related to uncertainty or variation, it may always originate either inside or outside of a system. According to Chen and Everett (1991), causes for flexibility needs can be divided into two groups: environmental uncertainties with regard to marketing, and uncertainties with regard to the manufacturing process.

In the section below, various factors causing flexibility needs have been classified as either market or manufacturing related. This will be used in the next section as an aid in linking the different factors causing changes to related flexibility types.

\subsection{MARKET-RELATED FACTORS}

From the marketing perspective, Chen et al. (1992) define three different sources of flexibility needs:

1. increased product diversity;

2. short product life cycle; and

3. an increase in buyer concentration (resulting in variations in demand).

De Toni and Tonchia (1998) offer an extended list of market-related requests for flexibility:

- the variability of the demand (random or seasonal); 
- shorter life cycles of the products and technologies;

- wider range of products;

- increased customization; and

- $\quad$ shorter delivery times.

This is also mainly consistent with Gerwin's (1987) definition of uncertainties.

\subsection{MANUFACTURING PROCESS RELATED FACTORS}

From the manufacturing process point of view, three sources are discussed by Chen et al. (1992):

1. Focused manufacturing.

2. Manufacturing technology innovation.

3. Unexpected competitors.

Correa (1994) and Gerwin (1993) have indicated a number of internal factors requiring flexibility capabilities:

- uncertainty with respect to machine downtime;

- uncertainty of whether the material input meets the standards of the process;

- changes with regard to delivery times of raw materials; and

- variations in workforce.

\subsection{MANAGING VARIATIONS AND UNCERTAINTY}

The preceding section describes the various reasons for manufacturing companies to seek flexibility. In short, a number of authors have suggested that flexibility is needed to deal with intrinsic uncertainties and variability of outputs (Correa, 1994). This section aims to explain what approaches may be considered when requiring flexibility for handling the variations and uncertainties.

This part is divided into sections describing the proposed approaches to handle each of the uncertainty/variability discussed earlier. Each defined aspect of uncertainty/variability is linked to every related flexibility type (e.g. volume fluctuation to volume flexibility), which in turn is linked to proposed methods, tools, and techniques to attain that required flexibility. 